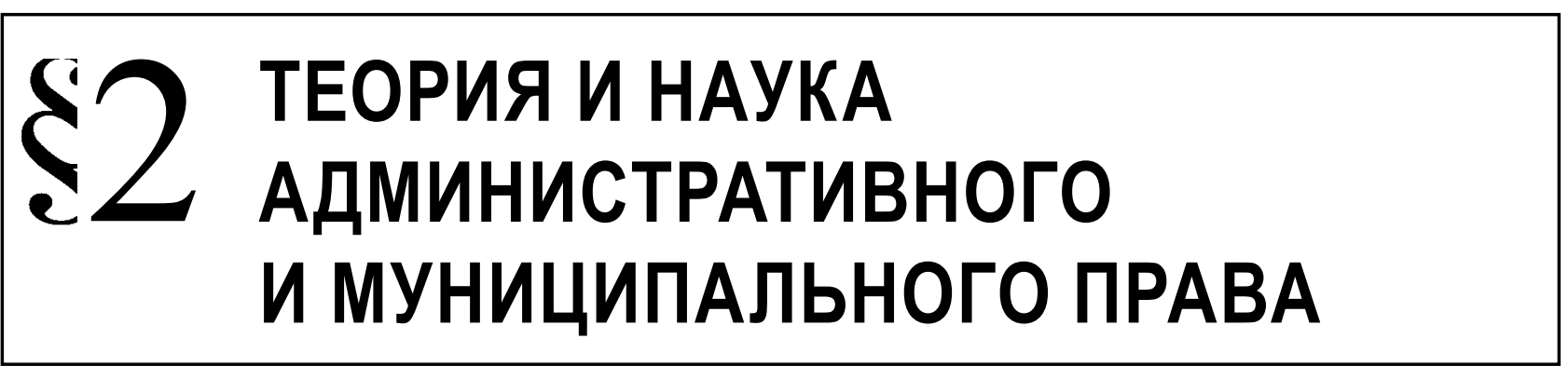

УДК: 342.922

Воронин И.К.

\title{
ТЕОРЕТИКО-ПРАВОВЫЕ АСПЕКТЫ ПРАВОВОГО АКТА УПРАВЛЕНИЯ (НА ПРИМЕРЕ ГОСУДАРСТВЕННОЙ РЕГИСТРАЦИИ ПРАВ НА НЕДВИЖИМОЕ ИМУЩЕСТВО И СДЕЛОК С НИМ)
}

\begin{abstract}
Аннотация. В статье проводится теоретический анализ акта управления и его роль в государственной регистрации прав на недвижимое имущество и сделок с ним. Анализ признаков акта управления, административно-правового акта, а также государственной регистрации прав на недвижимое имущество и сделок с ним позволил выработать новый подход к определению государственной регистрации прав на недвижимое имущество и сделок с ним, как правового административного акта ненормативного характера и индивидуальной направленности, имеющий силу. В работе использовались как общенаучные методы исследования (анализ, синтез, системно-структурный и функциональный подходы), так и специальные, применяемые в правоведении (сравнительно-правовой, формально-юридический и иные методы научного познания). Особым вкладом автора в исследование данной темы является представление государственной регистрации прав на недвижимое имущество и сделок с ним как правового административного акта ненормативного характера и индивидуальной направленности, имеющего правоустанавливающую силу, действиями "специального уполномоченного государственного органа", то есть представляет собой административный (управленческий) процесс.
\end{abstract}

Ключевые слова: недвижимое имущество, акт управления, регистрация прав, административно-правовой акт, законность, подзаконность, правовой акт, юридический акт, правоподтверждающий акт, административные правоотношения.

Abstract. The author analyzes the management act and its role in the state registration of real estate ownership and transactions. The analysis of the indications of the management act, the administrative-legal act, and the state registration of real estate ownership and transactions allows developing the new approach toward defining the state registration of real estate ownership and transactions as a legal administrative act of a nonnormative character and individual orientation. The author applies general scientific methods (analysis, synthesis, the system-structural and functional approaches), and special methods of jurisprudence (comparative-legal, formal-logical and other methods of scientific cognition). The special contribution of the author is the consideration of the state registration of real estate ownership and transactions as an administrative legal act of a nonnormative character, individual orientation, and constitutive effect, which is implemented through the "special authorized public agency"; thus, it is the administrative (managerial) process.

Key words: real estate, management act, registration of ownership, administrative-legal act, legality, bylaw, element of law, legal act, evidence act, administrative legal relations.

И 3 определения правового акта управления (административный акт) следует, что это основанное на законах одностороннее, юридически-властное волеизъявление уполномоченного представителя исполнительной власти, которое направлено на установление административно-правовых норм или возникновение, изменение и прекращение административноправовых отношений в целях реализации задач и функций государственно-управленческой дея- тельности. Для более детального исследования понятия государственная регистрация прав на недвижимое имущество и сделок с ним (далее регистрация прав) следует его рассмотреть и в качестве правового акта управления.

Правовая природа правового акта управления являет собой вариант юридического оформления управленческих решений [2]. В свою очередь, субъект системы исполнительной власти (орган или должностное лицо) путем его издания решает воз- 
никающие в процессе управленческой деятельности общие или индивидуальные вопросы с целью реализации поставленных задач. В этом случае правовые акты управления издаются только полномочными субъектами системы исполнительных органов власти в пределах компетенции. Правовой акт управления, в сущности подзаконный акт, издается исключительно полномочным субъектом представляющим исполнительную власть и исключительно в соответствии с Конституцией РФ, иными нормативными правовыми актами.

Правовой акт управления проявляет в себе властную природу государственно-управленческой деятельности, т.к. это волеизъявление характеризующееся как одностороннее и юридически-властное, изданное соответствующим представителем исполнительной власти, находит свое выражение именно в нем [8].

Юридически-властное предписание субъекта исполнительной власти, обязательно для лица к кому оно адресовано, оно закрепляет правило поведения в сфере государственного управления. Отметим, что правовой акт управления предназначен для создания юридической основы для возникновения, изменения или прекращения публичных или частных общественных отношений (содержит соответствующие административно-правовые нормы), либо предназначен для установления юридического факта, который непосредственно порождает, изменяет или прекращает конкретизированные в норме правоотношения. Правовой акт управления требует издания в форме письменного юридического документа[16], что вызывает необходимость следования определенным, официально установленным правилам (процедурам), которые предусматривают особый порядок подготовки и обсуждения проекта, проведения экспертиз, утверждения и. т.д. Но правовые акты управления могут быть выражены и в устной форме (к примеру, в служебных отношениях между непосредственным руководителем и его подчиненным ему служащим). Правовые акты управления нередко характеризуются и как конклюдентные повеления[19], не имеющие характера письменного акта (сигналы светофора, свисток сотрудника полиции, дорожный знак и т.п.).

Следует заметить, что в большей своей массе конклюдентные повеления не рассматриваются в качестве правовых актов управления, т.к. в них получают опосредствованное выражение соответствующие административно-принудительные меры, направленные на обеспечение общественной безопасности и порядка в сфере государственного управления [17]. В свою очередь, неисполнение этих предписаний может за собой явить издание правового акта (к примеру, о привлечении к административной ответственности).
Правовые акты управления по всеохватности их воздействия не могут быть ограничены только сферой государственного управления. Зачастую ими регламентируются индивидуальные стороны или особенности общественных отношений, компонующих предмет не только административного, а прочих отраслей отечественного права [13]. Превалирующе это касается финансовых, трудовых, частично земельных, природоохранительных и других видов общественных отношений.

Возвращаясь к самому понятию и признакам правового акта управления следует отметить, что существенная сложность в формулировании понятия правового акта управления (административного акта) обстоит в отсутствии его законодательно закрепленного термина отечественным законодателем. С тем, формулируя такое понятие, ученые исходят, за частую, из хронологически сформировавшейся теории административного акта, т.е. принимают за основу его базальные признаки, которые многогранно характеризуют данный административно-правовой феномен. С принятием указанных доминант представляется возможным дать следующую формулировку понимания правового акта управления [7].

Административный акт (правовой акт управления) - правовой акт, предназначенный для регулирования управленческих отношений или разрешения конкретного управленческого дела (спора), установления нового правового статуса субъект права, имеющий государственно-властный характер, издаваемый субъектом публичного управления в одностороннем административном порядке уполномоченным на то органом и должностным лицом в соответствии с установленными процедурами (в пределах управленческого процесса) в целях достижения целей управления, решения его задач и реализации функций управления.

Правовой акт управления (административный акт) [1] имеет ряд характерных признаков.

1. Правовые акты представляют собой управленческие решения, подготовленные и принятые (утвержденные) в соответствии с установленными правилами управленческого процесса для решения конкретной задачи управления и реализации функций управления.

2. Правовые акты принимаются уполномоченными субъектами публичного управления (органами государственного управления или местного самоуправления, их должностными лицами) в рамках предоставленной законами и иным нормативным актом компетенции. Административные акты могут приниматься как единолично конкретным лицом (орган или должностное лицо), так и коллегиально (совместно). 
3. Принимаются правовые акты управления в одностороннем порядке, т.е. специальные органы публичного управления или должностные лица принимают административные акты и контролируют его исполнение. Административный акт - это одностороннее волеизъявление, не требующее наличия согласия лиц, которые являются в конкретном случае объектом управленческой деятельности.

4. Правовые акты управления - юридические властные волеизъявления органа публичной администрации, в которых проявляется его государственно-властные полномочия. Следует выделять две формы существования и осуществления управленческих актов. Во-первых, административные акты Есть способ воплощения воли административно-управляющего субъекта, т.е. он являет собой акт, фактическое действие. Во-вторых, такое волеизъявление претворяется в жизнь уже после принятия административного акта в ходе исполнения и проведения в жизнь вводимого актом правового предписания. Волеизъявление субъекта проявляется в акте управления как в документе юридического свойства, служащий формой такого волеизъявления (в т.ч. и направленный к субъектам административного права) [30]. Правовые акты управления обладают государственно-властной характеристикой. Это означает, что его происхождение детерминировано общественными и государственными интересами (публичный интерес) и нацелено на урегулирование определенных отношений, закрепление общеобязательных правил поведения или разрешение конкретного вопроса или же спора, возникшего в рамках реализации функций исполнительной власти и всей системы публичного управления. Субъект принимая правовой акт управления, издает или утверждает административный акт, осуществляя таким образом государственную власть, которая как известно, характеризуется обязательностью исполнения позитивных законов, предписаний властного характера, действий и решений.

5. Правовые акты управления содержат правила ответственного поведения, правые нормы в публичном управлении, либо регламентируют конкретное (разовое) управленческое отношение. Императивность правовых актов обусловлено содержанием обязательного юридического властного предписания, которое подлежит безусловному исполнению.

6. Правовые акты управления устанавливает пределы надлежащего (должного) поведения субъектов в сфере государственного управ- ления; они создают правовую (легитимную) основу к возникновению, изменению или прекращению административно-правовых отношений; становятся юридическим фактом, которым непосредственно порождается, изменяется, прекращается такие правоотношения.

7. Законность и подзаконность правовых актов управления. Правовые акты управления подзаконны, т.е. он могут быть изданы полномочными субъектами исполнительной власти только в соответствии с Конституцией РФ, федеральными законами, международными договорами и другими законодательными актами, указами Президента РФ, постановлениями Правительства РФ, законодательными и иными нормативными актами субъектов РФ (уставами субъектов РФ, их законами), нормативными актами вышестоящих звеньев исполнительной власти в интересах обеспечения и исполнения содержащихся в них предписаний. Административные акты принимаются на основе законов соблюдением порядка, устанавливаемом нормативными актами (в рамках управленческого процесса), и обеспечивают исполнение или применение законов. С тем же правовые акты управления играют весомую роль в процессах реализации содержащихся в законах норм административного права. «Конкретизирующая роль» административного акта сводится к тому, что в нем широкий круг вопросов находит свою точечную детализацию, точно устанавливаются механизмы реализации предписания (норм), которые содержатся в законодательных актах, указах, постановлениях. Не редки случаи регламентации правовым актом управления отдельных сторон общественного отношения, среди прочих, формирующего, предмет не только административного, но и иных отраслей российского права (экологического, земельного, коммерческого, трудового, финансового, фискального). В сеем и находится творческий характер процедур принятия административного акта, потому как степень познания детерминант принятия такого акта, целесообразность его существования, необходимость, вероятность негативных результатов от действия, в большую зависимость ставит качество всей управленческой деятельности.

8. Правовые акты управления представляют собой разновидность юридического документа, используемого в процессе осуществления деятельности органа управления (его должностного лица) и представляющий собой справку, заключение, докладную записку, протокол, 
акт ревизии, инвентаризации, проверки и т.д., который фиксирует определенные факты (обстоятельство), имеет юридическое значение, но не содержит (в сравнении с нормативными правовыми актами) одностороннее государственно-властное обязательное к исполнению предписание.

9. Правовые акты управления имеют особую форму и процедуру принятия (утверждения). По обыкновению они издаются в письменной форме с соблюдением официально установленной процедуры, которая предусматривает порядок подготовки, согласований, обсуждений, экспертиз проектов актов управления, их утверждения, регистрации и обнародования. К некоторым актам управления (к примеру, акты федерального органа исполнительной власти) применяются правила процедурного характера регламентирующие подготовку, принятие, государственную регистрацию и опубликование. Некоторые положения устанавливающие порядок принятия акта управления прописаны, к примеру, в регламенте заседаний Правительства РФ, в регламенте проведения заседаний администрации субъекта РФ, инструкциях министерства, государственного комитета, федеральной службы и прочих органов власти. Законодательного закрепления, в прочем, общего правила подготовки и утверждения правовых актов до настоящего времени нет.

Так, в Федеральный закон «0 государственной регистрации прав на недвижимое имущество и сделок с ним» [27] (далее - Закон о регистрации...) определяет государственную регистрацию прав как, юридический акт которым государством признается и подтверждается возникновение, ограничение (обременение), переход или прекращение права на недвижимое имущество в соответствии с Гражданским Кодексом Российской Федерации».

Следует заметить, что на пору принятия Закона о регистрации... (1997 г.) приведенное определение соответствовало уровню юридической науки и правоприменительной практики того времени. Но и не согласиться с авторами, считавшими, что приведенное определение не имеет изъянов мы не можем [5]. В частности, объективно отмечено, что понятие государственной регистрации базируется на термине «юридический акт», который не имеет однозначного смыслового толкования [4,6,25]. Как следствие этого, определение лишено своей специфики и государственная регистрация не воспринимается как административный акт. К тому же само определение государственной регистрации прав отсылает к Гражданскому кодексу. В то же время в понятии прямым и однозначным образом не устанавливается, имеет ли акт регистрации прав правоподтверждающий характер или только правоустанавливающий.

Словом «акт» обозначается 1) единичные действия, отдельные проявления какой-нибудь деятельности; 2) документы, которыми удостоверяют какие-нибудь факты. В первом смысле слова, акт - это, прежде всего, действие, хотя и одиночного характера. Во втором акцент делается на единичность такого действия, что свидетельствует больше о статичности, чем о динамичности возникающих при этом отношений. Если в первом смысле, слово акт, является более общеупотребимым словом, то во втором - более специализированным, правовым термином [26]. Поэтому, прежде всего, следует рассмотреть государственную регистрацию прав в узком правовом смысле этого слова.

В литературе юридического содержания распространено отождествление понятий «правовой» и «юридический». Наша позиция рассмотрения акта государственной регистрации прав как правового акта т.е. указываем на отождествление его с «юридическим актом», как это предусматривается Законом о регистрации....

Уточнение содержания понятия «государственная регистрация прав на недвижимое имущество и сделок с ним» дополняется тем, что регистрация:

1) связана с оборотом недвижимого имущества и порождает определенные юридические последствия, а именно: возникновение, изменение, переход или прекращение права на недвижимое имущество;

2) проводится специальным уполномоченным государственным органом - федеральный орган исполнительной власти, осуществляющий функции по государственной регистрации прав (статья 9 Закона о регистрации...) [27];

Отметим, что в отечественной юридической науке имеется и иной подход. Государственная регистрация прав ассоциируется с правоподтверждающим актом $[9,3,14,28,29]$, которым утверждается, что зарегистрировать можно только то, что существует, а то, что существует (имеется в виду, право) надо не устанавливать, а подтверждать. Однако приверженцы указанного подхода не игнорируют одно обстоятельство: наступление правовых последствий возникает только с момента государственной регистрации прав. Регистрация права и само право нераздельны. Таким образом мнение, что государственная регистрация прав является правоустанавливающим актом, становится очевидным.

Возвращаясь к теории права вообще и административного права, в частности, юридический акт - это волевое правомерное действие субъектов правоотношения, которое является, по своей при- 


\section{Административное и муниципальное право 2 (98) 2016}

роде юридическим фактом[20], порождающим возникновение (изменение, прекращение) конкретных правоотношений. Следовательно, акт государственной регистрации прав - юридический факт, порождающий административное правоотношение.

В отечественной правовой доктрине административные правоотношения определяется как «... урегулированные нормами административного права управленческие общественные отношения, складывающиеся в сфере реализации исполнительной власти»[24]. Общепринятые характеристики административно-правовых отношений можно отнести и к государственной регистрации прав, но с определенными условностями, так как последние обладают собственной спецификой.

Первая специфика, отличие административноправовых отношений вообще, от отношений связанных с государственной регистрацией прав на недвижимое имущество и сделок с ним, усматривается в том, что при государственной регистрации прав возникает два взаимоувязанных правоотношения:

1) правоотношение, возникает между лицами (физическими и юридическими), которые заключили сделку с объектом недвижимого имущества и в связи с чем, обратились с заявлением о государственной регистрации сделки в федеральный орган исполнительной власти, который уполномочен проводить государственную регистрацию прав;

2) правоотношение, возникаем между федеральным органом регистрирующим право, и заявителями, которые получают документ с правоустанавливающей отметкой государственного органа (регистратора) и свидетельство о государственной регистрации - акт которым признается и подтверждается государством возникновение, ограничение (обременение), перехода или прекращения права на недвижимое имущество.

Вторая специфика в том, что данные правоотношения, характеризуемые как административные по своей природе, не могут существовать отдельно от гражданско-правовых (имущественных) отношений [5].

Третья специфика заключается в «горизонтальности» данных административных правоотношений $[9,10,29]$. Это прослеживается в том, что между субъектами (физическими или юридическими), которые имеют право на недвижимое имущество или заключающие сделки с ним, и органом осуществляющим государственную регистрацию нет отношений типа «власть-подчинение». Вместе с тем, одну сторону - физическое или юридическое лицо - закон побуждает правом на государственную регистрацию прав, а другую - орган государственной регистрации - обязывает, при наличии достаточных оснований, произвести регистрацию этих прав в соответствии с законом.

Изучение действующих норм законодательства регулирующего государственную регистрацию права на недвижимое имущество и сделок с ним, а также рассмотрение практики его реализации подтверждает то, что между правами и их государственной регистрацией существует достаточно устойчивая юридическая связь. Теорией административного права, как и Законом о регистрации (статья 4) императивно закреплена обязательность процедуры государственной регистрации права на недвижимое имущество и сделок с ним. Меры государственного принуждения за неисполнение этой обязанности не установлены. Заявитель - добросовестный приобретатель недвижимого имущества, может не регистрировать свое имущество и не нести при этом никакой ответственности, так как статьей 16 Закона о регистрации установлен заявительный характер государственной регистрации[27].

Статьей 20 Закона о регистрации.... закреплен подробный перечень обстоятельств, наличие которых является препятствием для государственной регистрации права. Регистрирующий государственный орган непосредственно принимает участие в административно-правовом регулировании общественных отношений, складывающихся в ходе оборота недвижимого имущества на уровне однозначных правоотношений определенных субъектов права.

Издание индивидуального правового акта уполномоченным государственным регистрирующим органом дает начало возникновения, изменения и прекращения правоотношениям, связанным с изменением правового отношения субъекта к недвижимому имуществу, обладает непосредственным правоустанавливающим значением [21].

Решение, реализованное в процессе осуществления процедур государственной регистрации, уполномоченным органом регистрации прав на недвижимое имущество есть индивидуальный административный акт, который представляет собой решение конкретного вопроса, обращенное к конкретным лицам (заявителям).

Акт государственной регистрации прав распространяет свое действие только на тех лиц, которые вступают в правоотношения с собственником недвижимого имущества [11], и на него самого.

Акт государственной регистрации прав является ненормативным административным актом [13], поэтому его можно оспорить в административном порядке. При этом оспаривается не зарегистрированное право, а акт государственного органа(уполномоченного на осуществление государственной регистрации). 
Исходя из вышеизложенного, предлагается вариант определения: «Государственная регистрация прав на недвижимое имущество и сделок с ним правоустанавливающий административно-правовой акт, осуществляемый специально уполномоченным государственным органом в целях признания и подтверждения государством возникновения, ограничения (обременения), перехода или прекращения прав на недвижимое имущество в соответствии с законодательством Российской Федерации».

Важно сделать акцент на то, что, будучи административно-правовым актом, государственная регистрация должна осуществляться в соответствии с российским законодательством вообще, а не только с ГК РФ. Фокусируя внимание на ГК РФ, законодатель дезориентирует правоприменительную практику. С другой стороны, из всех особенностей государственной регистрации как административно-правового акта нами выделяется самая важная - правоустанавливающий характер этого акта, так как из самого понятия государственной регистрации не возникает непосредственно то обстоятельство, что это есть правоустанавливающий акт.
Только факт государственной регистрации прав на недвижимое имущество и сделок с ним порождает, изменение или прекращение прав и обязанностей субъектов описываемых правоотношений. По сему акт государственной регистрации не может считаться особливо правоподтверждающим актом.

Государственная регистрация прав на недвижимое имущество и сделок с ним, являясь правоустанавливающим актом, «автоматически» подтверждает и права на такое имущество, и производимые с ним сделки. Существенным является и то, что в предложенная дефиниция включает указание на то, что регистрация исполняется действиями «специального уполномоченного государственного органа», то есть представляет собой административный (управленческий) процесс.

Таким образом, государственная регистрация прав на недвижимое имущество и сделок с ним следует воспринимать в виде (или представляет собой) правового административного акта ненормативного характера и индивидуальной направленности, имеющего правоустанавливающую силу.

\section{Библиография:}

1. Абдурахманов А.А. Правовые акты управления в механизме административно-правового регулирования общественных отношений / Монография. М.: ВНИИ МВД России, 2005. С. 4.

2. Арзамасов Ю.Г. О правовой природе актов государственного управления // Государственная власть и местное самоуправление. 2007. № 5. С. 3-9.

3. Болтанова Е.С. Права на земельные участки: теория, законодательство и практика его применения. Ростов-наДону: Феникс, 2006. С. 96.

4. Большая юридическая энциклопедия; Мицкевич А.В. Нормативные акты Советского государства. М., 1958.

5. Борисов Г.А. Методологические проблемы права на недвижимое имущество и сделок с ним / Г.А. Борисов, Я.В. Пойминов // История государства и права. 2008. № 2. С. 12-14.

6. Васильев Р.Ф. Акты правления. Значение, проблема исследований, понятие / Р.Ф. Васильев. М.: Изд-во Моск. ун-та, 1987. 141 c.

7. Галлиган Д. Административное право: история развития и основные современные концепции / Д. Галлиган, В.В. Полянский, Ю.Н. Старилов. М.: Юристъ, 2002. С. 201-202.

8. Глушенков А.А. Административно-правовые формы и методы государственно-правленческой деятельности // Совершенствование административно-правового обеспечения деятельности сотрудников ОВД" научно-практической конференции (2011, Орел) Изд-во: ОрЮИ МВД России, 2012. С. 41-46.

9. Гришаев С.П. Государственная регистрация вещных прав // Журнал российского права. 2006. № 10. С. 87.

10. Зеленцов А.Б. Административно-правовой спор (теоретико-методологические подходы к исследованию) // Правоведение. 2000. № 1. С. 68-79.

11. Зеленцов А.Б. Теоретические проблемы административно-правового спора // Государство и право. 1998. № 12. C. 29-31.

12. Ильченко А.Л. Оспаривание в суде зарегистрированного права на недвижимое имущество // Нотариус. 2004. № 5. С. 16.

13. Кононов П.И. К вопросу о предмете, методе и месте административного права в системе отраслей российского права // Проблемы современного административного права. Сборник научных статей / Отв. ред.: Машаров И.М.; Науч. ред.: Кононов П.И. Киров, 2005. С. 53.

14. Кононов П.И. О понятии и признаках ненормативного административно-правового акта // Административное судопроизводство в Российской Федерации: развитие теории и формирование административно-процессуального законодательства. Вып. 7. Воронеж: Изд-во Воронеж. гос. ун-та, 2013. С. 529.

15. Крылов С. Регистрация прав на недвижимость: понятие и проблемы // Российская юстиция. 1997. № 10. С. 31.

16. Лапшинов Э.В. К проблеме понятия юридического документа // Источники права. Материалы международной научно-практической конференции, 15 ноября 2008 г., г. Абакан / Науч. ред.: Сергеев Д.Б. Абакан: Изд-во Хакасск. гос. ун-та, 2009. С. 59.

17. Леженин А.В. О принудительном характере административно-предупредительных мер / Всероссийская научнопрактическая конференция «Современные проблемы борьбы с преступностью». Сборник материалов (юридические науки) - Воронеж: Изд-во Воронеж. ин-та МВД России, 2004. С. 91.

18. Ожегов С.И. Словарь русского языка. М.: Русский язык, 1988. С. 20. 


\section{Административное и муниципальное право 2 (98) • 2016}

19. Пахомов М.С. Конклюдентные действия в сфере реализации права // Вестник Московского университета МВД России. М.: Изд-во Моск. ун-та МВД России, 2009. № 4. С. 116.

20. Петров Г.И. Сущность советского административного права / Отв. ред.: О.С. Иоффе. Л.: Изд-во Ленингр. ун-та,1959. С. 87-88.

21. Петров Г.И. Советские административно-правовые отношения. Л.: Изд-во ЛГУ, 1972. С. 24.

22. Пискунова М.Г. Государственная регистрация прав на недвижимое имущество и сделок с ним как правоприменительная деятельность учреждений юстиции // Государственная регистрация прав на недвижимость: теория и практика. Сборник статей / Сост.: Е.А. Киндеева, М.Г. Пискунова. М.: Ось-89, 2005. С. 285-286.

23. Пойминова Я.В. Государственная регистрация прав как правовая форма реализации властных полномочий: методологические проблемы // Нотариус. 2000. № 3. С. 36-37.

24. Попов Л.Л., Мигачев Ю.И., Тихомиров С.В. Административное право России Уч. 2-е изд., перераб. и доп. / Л.Л. Попов, Ю.И. Мигачев, С.В. Тихомиров. М.: Проспект, 2009. С. 57-59.

25. Тихомиров Ю.А., Котелевская И.В. Правовые акты. Учебно-практическое и справочное пособие. М., 1999.

26. Толковый словарь русского языка / Под ред. Д.Н. Ушакова. Т. 1. М.: ОГИЗ, 1935. С. 23.

27. Федеральный закон «О государственной регистрации прав на недвижимое имущество и сделок с ним» № 122 -Ф3 от 21.07.1997 // СПС «Гарант».

28. Штыка А. Обжалование ненормативного акта или спор о праве? // ЭЖ-Юрист. 2005. № 13.

29. Шейнин А.Б. Государственная регистрация недвижимости: создает право или подтверждает его? // Журнал российского права. 2004. № 10. С. 61.

30. Ястребов О.А. Публичный субъект и частный субъект административного права // Вестник Московского университета МВД России. : Изд-во Моск. ун-та МВД России. 2010. № 1. С. 175-176.

31. Синельникова В.Н. Модернизация системы государственной регистрации прав на недвижимое имущество и сделок с ним: практические вопросы // Право и политика. 2014. № 11. С. 1745-1755. DOI: 10.7256/18119018.2014.11.13092.

32. Тамазян С.К. Проблемы обжалования акта государственной регистрации прав на недвижимое имущество и сделок с ним // Урбанистика и рынок недвижимости. 2014. № 2. C. 50-57. DOI: 10.7256/2313-0539.2014.2.10039.

33. Тамазян С.К., Субоч Е.Л. Правовая природа государственной регистрации прав на недвижимость // Урбанистика и рынок недвижимости. 2014. № 2. C. 84-91. DOI: 10.7256/2313-0539.2014.2.10176.

\section{References (transliterated):}

1. Abdurakhmanov A.A. Pravovye akty upravleniya $\mathrm{v}$ mekhanizme administrativno-pravovogo regulirovaniya obshchestvennykh otnoshenii / Monografiya. M.: VNII MVD Rossii, 2005. S. 4.

2. Arzamasov Yu.G. O pravovoi prirode aktov gosudarstvennogo upravleniya // Gosudarstvennaya vlast' i mestnoe samoupravlenie. 2007. № 5. S. 3-9.

3. Boltanova E.S. Prava na zemel'nye uchastki: teoriya, zakonodatel'stvo i praktika ego primeneniya. Rostov-na-Donu: Feniks, 2006. S. 96.

4. Bol'shaya yuridicheskaya entsiklopediya; Mitskevich A.V. Normativnye akty Sovetskogo gosudarstva. M., 1958.

5. Borisov G.A. Metodologicheskie problemy prava na nedvizhimoe imushchestvo isdeloks nim/G.A.Borisov, Ya.V.Poiminov // Istoriya gosudarstva i prava. 2008. № 2. S. 12-14.

6. Vasil'ev R.F. Akty pravleniya. Znachenie, problema issledovanii, ponyatie / R.F. Vasil'ev. M.: Izd-vo Mosk. un-ta, 1987.141 c.

7. Galligan D. Administrativnoe pravo: istoriya razvitiya i osnovnye sovremennye kontseptsii / D. Galligan, V.V. Polyanskii, Yu.N. Starilov. M.: Yurist", 2002. S. 201-202.

8. Glushenkov A.A. Administrativno-pravovye formy i metody gosudarstvenno-pravlencheskoi deyatel'nosti // Sovershenstvovanie administrativno-pravovogo obespecheniya deyatel'nosti sotrudnikov OVD" nauchno-prakticheskoi konferentsii (2011, Orel) Izd-vo: OrYuI MVD Rossii, 2012. S. 41-46.

9. Grishaev S.P. Gosudarstvennaya registratsiya veshchnykh prav // Zhurnal rossiiskogo prava. 2006. № 10. S. 87.

10. Zelentsov A.B. Administrativno-pravovoi spor (teoretiko-metodologicheskie podkhody k issledovaniyu) // Pravovedenie. 2000. № 1. S. 68-79.

11. Zelentsov A.B. Teoreticheskie problemy administrativno-pravovogo spora // Gosudarstvo i pravo. 1998. № 12. S. 29-31.

12. Il'chenko A.L. Osparivanie v sude zaregistrirovannogo prava na nedvizhimoe imushchestvo // Notarius. 2004 . № 5. S. 16.

13. Kononov P.I. K voprosu o predmete, metode i meste administrativnogo prava v sisteme otraslei rossiiskogo prava // Problemy sovremennogo administrativnogo prava. Sbornik nauchnykh statei / Otv. red.: Masharov I.M.; Nauch. red.: Kononov P.I. Kirov, 2005. S. 53.

14. Kononov P.I. O ponyatii i priznakakh nenormativnogo administrativno-pravovogo akta // Administrativnoe sudoproizvodstvo v Rossiiskoi Federatsii: razvitie teorii i formirovanie administrativno-protsessual'nogo zakonodatel'stva. Vyp. 7. Voronezh: Izd-vo Voronezh. gos. un-ta, 2013. S. 529.

15. Krylov S. Registratsiya prav na nedvizhimost': ponyatie i problemy // Rossiiskaya yustitsiya. 1997. № 10. S. 31.

16. Lapshinov E.V. K probleme ponyatiya yuridicheskogo dokumenta // Istochniki prava. Materialy mezhdunarodnoi nauchno-prakticheskoi konferentsii, 15 noyabrya 2008 g., g. Abakan / Nauch. red.: Sergeev D.B. Abakan: Izd-vo Khakassk. gos. un-ta, 2009. S. 59.

17. Lezhenin A.V. O prinuditel'nom kharaktere administrativno-predupreditel'nykh mer / Vserossiiskaya nauchnoprakticheskaya konferentsiya «Sovremennye problemy bor'by s prestupnost'yu». Sbornik materialov (yuridicheskie nauki) - Voronezh: Izd-vo Voronezh. in-ta MVD Rossii, 2004. S. 91.

18. Ozhegov S.I. Slovar' russkogo yazyka. M.: Russkii yazyk, 1988. S. 20.

19. Pakhomov M.S. Konklyudentnye deistviya v sfere realizatsii prava // Vestnik Moskovskogo universiteta MVD Rossii. M.: Izd-vo Mosk. un-ta MVD Rossii, 2009. № 4. S. 116.

20. Petrov G.I. Sushchnost' sovetskogo administrativnogo prava / Otv. red.: O.S. Ioffe. L.: Izd-vo Leningr. un-ta,1959. S. 87-88.

21. Petrov G.I. Sovetskie administrativno-pravovye otnosheniya. L.: Izd-vo LGU, 1972. S. 24. 
22. Piskunova M.G. Gosudarstvennaya registratsiya prav na nedvizhimoeimushchestvo i sdelok s nim kak pravoprimenitel'naya deyatel'nost' uchrezhdenii yustitsii // Gosudarstvennaya registratsiya prav na nedvizhimost': teoriya i praktika. Sbornik statei / Sost.: E.A. Kindeeva, M.G. Piskunova. M.: Os'-89, 2005. S. 285-286.

23. Poiminova Ya.V. Gosudarstvennaya registratsiya prav kak pravovaya forma realizatsii vlastnykh polnomochii: metodologicheskie problemy // Notarius. 2000. № 3. S. 36-37.

24. Popov L.L., Migachev Yu.I., Tikhomirov S.V. Administrativnoe pravo Rossii Uch. 2-e izd., pererab. i dop. / L.L. Popov, Yu.I. Migachev, S.V. Tikhomirov. M.: Prospekt, 2009. S. 57-59.

25. Tikhomirov Yu.A., Kotelevskaya I.V. Pravovye akty. Uchebno-prakticheskoe i spravochnoe posobie. M., 1999.

26. Tolkovyi slovar' russkogo yazyka / Pod red. D.N. Ushakova. T. 1. M.: OGIZ, 1935. S. 23.

27. Federal'nyi zakon «O gosudarstvennoi registratsii prav na nedvizhimoe imushchestvo i sdelok s nim» № $122-\mathrm{FZ}$ ot 21.07.1997 // SPS «Garant».

28. Shtyka A. Obzhalovanie nenormativnogo akta ili spor o prave? // EZh-Yurist. 2005. № 13.

29. Sheinin A.B. Gosudarstvennaya registratsiya nedvizhimosti: sozdaet pravo ili podtverzhdaet ego? // Zhurnal rossiiskogo prava. 2004. № 10. S. 61.

30. Yastrebov O.A. Publichnyi sub"ekt i chastnyi sub"ekt administrativnogo prava // Vestnik Moskovskogo universiteta MVD Rossii. : Izd-vo Mosk. un-ta MVD Rossii. 2010. № 1. S. 175-176.

31. Sinel'nikova V.N. Modernizatsiya sistemy gosudarstvennoi registratsii prav na nedvizhimoe imushchestvo i sdelok s nim: prakticheskie voprosy // Pravo i politika. 2014. № 11. C. 1745-1755. DOI: 10.7256/1811-9018.2014.11.13092.

32. Tamazyan S.K. Problemy obzhalovaniya akta gosudarstvennoi registratsii prav na nedvizhimoe imushchestvo i sdelok s nim // Urbanistika i rynok nedvizhimosti. 2014. № 2. C. 50-57. DOI: 10.7256/2313-0539.2014.2.10039.

33. Tamazyan S.K., Suboch E.L. Pravovaya priroda gosudarstvennoi registratsii prav na nedvizhimost' // Urbanistika i rynok nedvizhimosti. 2014. № 2. C. 84-91. DOI: 10.7256/2313-0539.2014.2.10176. 